\title{
Important Improvements of Helium Mass Spectrometry Test for Sealability
}

\author{
Genglin Wang ${ }^{1}$, Ningbo $\mathrm{Li}^{2}$, Wenbin $\mathrm{Li}^{1}$, Fei $\mathrm{Li}^{3}$, Weigang $\mathrm{Wu}^{2}$, Yongmin $\mathrm{Liu}^{4}$ \\ ${ }^{1}$ Corporation Headquarter, Beijing Keytone Electronic Relay Corporation, Beijing, China \\ ${ }^{2}$ Design Center, Beijing Keytone Electronic Relay Corporation, Beijing, China \\ ${ }^{3}$ Production Center, Beijing Keytone Electronic Relay Corporation, Beijing, China \\ ${ }^{4}$ Administration Office, Beijing Keytone Electronic Relay Corporation, Beijing, China \\ Email address: \\ wgl68860377@126.com (Genglin Wang), liningbozdh@126.com (Ningbo Li)
}

\section{To cite this article:}

Genglin Wang, Ningbo Li, Wenbin Li, Fei Li, Weigang Wu, Yongmin Liu. Important Improvements of Helium Mass Spectrometry Test for Sealability. Journal of Electrical and Electronic Engineering. Vol. 7, No. 1, 2019, pp. 8-22. doi: 10.11648/j.jeee.20190701.12

Received: December 11, 2018; Accepted: January 15, 2019; Published: February 13, 2019

\begin{abstract}
Helium mass spectrometry test is one of the most commonly used electronic component sealability tests. However, it has a few obvious problems. For components passed test, their reliable storage life time is very uneven. During the test, feasibility of removing absorbed helium is low. High missing detection rate reduces the reliability of the test. Combined relevant patents and papers, and on the basis of theoretical derivation, verified by experimental and case analysis, this paper proposed a series of improvements. They include improvement fine-leak test basic criterion, quantitative determination of the maximum detection-waiting time for fine-leak test, a combination test method by using argon as gross-leak test tracer gas and helium as fine-leak test tracer gas as the core improvement, methods of reducing and preventing detection missing in the gross-leak test and fine-leak test.
\end{abstract}

Keywords: Sealability of Electronic Components, Helium Mass Spectrometry Test, Fine-Leak Test Basic Criterion, Maximum Detection-Waiting Time, Gross/Fine-Leak Combination Test, Argon as Gross-Leak Test Tracer Gas, Detection Missing Prevention

\section{Introduction}

The sealability test of electronic components is generally divided into fine-leak test and gross-leak test. The fine-leak test usually employs helium mass spectrometry, Kr85 radioisotope and light leakage test. The helium mass spectrometry fine-leak test has the advantage of relatively high sensitivity, non-destructive, harmless and high efficiency. Among the various methods for gross-leak test, the fluorocarbon bubble method is most commonly used due to its high sensitivity. However, for a half century, many professionals have been repeatedly pointed out [1-6] that the criterions for fine-leak test specified by the International Electrotechnical Commission (IEC) standards, United States military standards, and Chinese military standards are too loose. Usually about $5 \%$ to $15 \%$ of the products passed the standard test have the equivalent standard leak rate close to the criterion. After dozens of days screening or longer time storage, the internal water vapor content of the product may exceed 5000ppm limitation, which causes the product batch cannot be delivered or reduced reliability in the future usage.

The experimental study in [7] shows that the fluorocarbon bubble method guarantees the minimum equivalent standard leakage rate $\mathrm{L}_{0}$, which can be taken as $1.0 \mathrm{~Pa} \cdot \mathrm{cm}^{3} / \mathrm{s}$ as specified by IEC standard [8]. However, the test success rate is only about $80 \%$. Meanwhile, it may cause some problems such as liquid phase temperature impact on the test piece, infiltration of fluorocarbons, and detection missing due to the leak hole clogged by the fluorocarbon.

In fact, the statistics of ORS Inc. based on the "DSCC TM-1018" database [9] show that by 2008, among the 9773 military components which passed sealability test, $14 \%$ of them internal water vapor exceeded the 5000ppm limitation; $2.3 \%$ had fluorocarbon inside, among which half exceeded internal water vapor limitation. Literature [10] made statistics according to the internal gas analysis data obtained from eight laboratories in 
United States and Europe, among 1889 samples with various packages, $10.7 \%$ of them with internal water vapor exceeded the limitation and $4.4 \%$ containing the fluorocarbon among which $42 \%$ water vapor exceeded the standard.

Because of detection missing or the criterion too loosed, too much water vapor or other harmful gas leaks into the component in the testing and storage process, causing the component to fail from time to time during storage and machine application [10-14].

For solving those problems, in the beginning of this century, the cumulative helium mass spectrometer combination leak detector (CHLD), the radioisotope Kr85 combination leak detector (Kr85) and the optical combination leak tester (OLT) have been developed. These leak detectors are suitable for the combination test of gross-leak test and fine-leak test and have higher sensitivity. The fluorocarbon bubble method is no longer used for gross-leak test. Method 1071.9 in MIL-STD-750-1 test standard [15], released in 2012, applied these methods and tightens the basic criterion of fine-leak --the equivalent standard leak rate $\mathrm{L}$ is tightened by 1.5 to 2 orders of magnitude; Method 1014.14 in MIL STD-883J test standard [16], released in 2013, tightened the basic criterion L of class $\mathrm{K}$ components by 1.5 to 2 orders of magnitude.

However, studies in the literature $[13,14,17,18]$ revealed a few unneglectable problems with these combination test methods.

First, the reliable storage life time of the qualified components is very uneven. The storage life time of the component, before their internal water vapor reaches $50 \%$ of environmental water vapor, with inner cavity volume $\mathrm{V}$ of 20 $\mathrm{cm}^{3}$ is 1000 times or 500 times as that of $0.002 \mathrm{~cm}^{3}$. In the other words, under the same environmental condition, the reliable storage life time of the component may differ 1000 to 500 times depends on their inner cavity volume. Moreover, in the good air environment which has a water vapor content of $10,000 \mathrm{ppm}$, the reliable storage life time of the sealed components having common inner cavity volume is far from high reliable components required, which causes a serious reliability issue.

The research in [13] and the literature $[17,18]$ indicates that the maximum detection-waiting time for the helium mass spectrometry test and accumulated helium mass spectrometry test specified in the standards $[15,16]$ is not only lack of theoretical basis but also in many cases, not guaranteed that it would be long enough to remove adequate absorbed helium from the surface of the test piece which makes sure the absorption leak rate $R_{a}$ is not more than $1 / 3$ of the measurement leakage rate criterion $R_{\max }$. This formed a serious feasibility problem.

What is more critical is the high rate of detection missing in gross- and fine-leak tests. In 2012 and 2013, Cooperated by Germany company Inficon and Keytone from Beijing, using Pernicka $-700 \mathrm{H}$ CHLD, several batches of components were tested in Germany and China. For the components failed gross-leak test employing the bubble method and subsequent internal gas analysis method, only $17 \%$ of them detected as gross-leak using CHLD. The detection missing rate of grossand fine-leak test reach $42.9 \%$. In NASA's research report [13, 14], the severity of detection missing problem while employing various combination test methods for retesting is highlighted.

Experiment was carried out with three types of micro-sealing components. When employing $\mathrm{Kr} 85$ test method, 5 of them were detected leakage in fine-leak test and 5 in gross-leak test. These samples were verified as sealability failure with residual gas analysis or internal gas analysis after repeated retesting by various methods. But in the combined retest of CHLD, Kr85 and OLT, some of failure components presented as sealability qualified in both gross- and fine-leak tests. The ration of detection missing, which is the number of times of leaking components tested as sealability qualified to the number of times tests carried out is shown in table 1 . Wherein, the "ND" means no data, and the CHLD and Kr85 data are based on the table on page 20 of the literature [14], the OLT data is based on the tables on pages 16,18 and 19 of the literature [14].

Table 1. The detection missing ratio of unqualified components in various combinations retest methods.

\begin{tabular}{llll}
\hline $\begin{array}{l}\text { sample package } \\
\text { Inner cavity volume }\end{array}$ & Detector & detection missing ratio in fine-leak test & detection missing ratio in gross-leak test \\
\hline TO-18 & CHLD & $8 / 10$ & $7 / 10$ \\
$0.0345 \mathrm{~cm}^{3}$ & Kr85 & $10 / 10$ & $10 / 10$ \\
& OLT & $1 / 5$ & $1 / 4(1 \mathrm{ND})$ \\
$\mathrm{TO}-5$ & CHLD & $0 / 10$ & $0 / 10$ \\
$0.2244 \mathrm{~cm}^{3}$ & Kr85 & $6 / 10$ & $6 / 10$ \\
& OLT & $3 / 5$ & $4 / 5$ \\
$\mathrm{UB}$ & CHLD & $10 / 10$ & $0 / 10$ \\
$0.0026 \mathrm{~cm}^{3}$ & Kr85 & $10 / 10$ & $0 / 10$ \\
\hline
\end{tabular}

Meanwhile, according to the detection missing data in the literature $[9,10]$, both gross- and fine-leak detection missing also happens in the initial test of various sealability test methods. Such a high ratio of detection missing seriously affects the credibility of the sealibility test.

Faced to such critical problems, the literature [19] pointed out: "The Contradiction in leak rate requirements is embarrassment which will not go away by ignoring it. So, what is going to be done about this?" The title of the literature [20] is "Questions?".

Based on Genglin Wang and his group's patents in China and United States, published articles and recent research, this paper analyzes the causes and mechanism of common problems in helium mass spectrometry test, discusses various 
methods on improvements.

The main focus is on the combination test by using helium as fine-leak tracer gas and argon as gross-leak tracer gas to prevent detection missing.

\section{Improvement on Fine-leak Test Basic Criterion}

The helium mass spectrometry fine-leak test by pressing helium is based on the molecular flow theory. The model is:

$$
R_{1}=\frac{L P_{E}}{P_{0}} \sqrt{\frac{M_{A}}{M_{H e}}}\left[1-\exp \left(-\frac{L t_{1}}{V P_{0}}\right) \sqrt{\frac{M_{A}}{M_{H e}}}\right] \exp \left(-\frac{L t_{2}}{V P_{0}} \sqrt{\frac{M_{A}}{M_{H e}}}\right)
$$

Where $R_{1}$ is the helium gas measured leak rate; $L$ is the equivalent standard leak rate; $\mathrm{P}_{\mathrm{E}}$ is the pressure of pressurizing helium for the component under test; $\mathrm{P}_{0}$ is the standard atmospheric pressure and $\mathrm{P}_{0}=1.013 \times 10^{5} \mathrm{~Pa} ; \mathrm{M}_{\mathrm{A}}$ is the air molar mass expressed in grams, $\mathrm{M}_{\mathrm{A}}=28.96 \mathrm{~g} ; \mathrm{M}_{\mathrm{He}}$ is the helium molar mass expressed in grams and $\mathrm{M}_{\mathrm{He}}=4.003 \mathrm{~g}$; $t_{1}$ is the pressurizing helium time; $t_{2}$ is the detection-waiting time from the removal pressure of pressing helium to the fine-leak test; $\mathrm{V}$ is the inner cavity volume of the component.

This equation is proposed by Howl, D. A and Mann, C. A in 1965 [21], and $M$ in the original equation is replaced by $M_{H e}$ here. The two complex exponential terms in equation (1) make it not so easy to understand and apply. The current standard uses $\mathrm{L}$ as the main variable and the basic criterion. Although $\mathrm{L}$ is adjustable for various $\mathrm{V}$, the reliable storage life is still extremely uneven for various $\mathrm{V}$.

In the literature [3], substituting the following expression to equation (1).

$$
L_{H e}=L \sqrt{\frac{M_{A}}{M_{H e}}}
$$

Since 2000 , the literature $[4,5]$ proposed that taking helium exchanges time constants

$$
\tau_{H e}=\frac{V P_{0}}{L} \sqrt{\frac{M_{H e}}{M_{A}}}
$$

as a primary variable to simplifies equation (1) as:

$$
R_{1}=\frac{V P_{E}}{\tau_{H e}}\left[1-\exp \left(-\frac{t_{1}}{\tau_{H e}}\right)\right] \exp \left(-\frac{t_{2}}{\tau_{H e}}\right)
$$

Under the common condition of $t_{1} \leqslant \frac{1}{5} \tau_{H e}, t_{2} \leqslant \frac{1}{10} \tau_{H e}$, using the power function expansion and simplifying [22], the approximate equation of $\mathrm{R} 1$ is obtained:

$$
R_{1}=\frac{V P_{E} t_{1}}{\tau_{H e}^{2}}
$$

In the similar way, for the pre-filling helium mass spectrometry of fine-leak test, the relationship between the measured leak rate $\mathrm{R}_{2}$ and $\tau_{\mathrm{He}}$ is:

$$
R_{2}=\frac{V k P_{0}}{\tau_{H e}} \exp \left(-\frac{t_{3}}{\tau_{H e}}\right)
$$

Where, $\mathrm{k}$ is the pre-filling helium ratio which is the ratio of the pre-filling helium partial pressure $\mathrm{P}_{\text {Hed }}$ to the pre-filling total pressure $\mathrm{P}_{0} ; \mathrm{t}_{3}$ is the detection-waiting time starting from the moment of sealing after pre-filling helium.

An approximate equation for $\mathrm{R}_{2}$ can be obtained under the common condition of

$$
\begin{aligned}
& t_{3} \leqslant \frac{1}{10} \tau_{H e} \\
& R_{2}=\frac{V k P_{0}}{\tau_{H e}}
\end{aligned}
$$

From 2013, rigor grade $\tau_{\mathrm{Hemin}}$, which is the minimum helium exchange time constant of the accepted components has been defined as the basic criterion for fine leak test [23]. When $\tau_{\mathrm{He}}=\tau_{\mathrm{Hemin}}, \mathrm{R}_{1}$ is obtained by the equation (4) (5), that is the accepted component characterization criterion of fine-leak test $\mathrm{R}_{1 \text { max }}$ for pressing helium method, wherein the maximum relative deviation of $\tau_{\text {Hemin }}$ derived from the approximate equation (5) is $-9.44 \% ; R_{2}$ obtained by the equation (6) and (7) is the accepted component characterization criterion of fine-leak test $\mathrm{R}_{2 \max }$ for pre-filling helium method, wherein the maximum relative deviation of $\tau_{\mathrm{Hemin}}$ derived from the approximate equation (7) is $-9.92 \%$ [22].

As pointed out in literature [24], with $\tau_{\mathrm{He}}$ as the main variable, "the new equation after transformation is more concise. The gas in/out of the sealed components is described by the helium exchange time constant as a physical process, which is similar to the charge and discharge of the capacitor in the electrical system. The new expression is more intuitive."

Taking $\tau_{\text {Hemin }}$ as the basic criterion and $\mathrm{R}_{1 \max }, \mathrm{R}_{2 \max }$ as the characterization criterions, the storage life uneven problem among different inner cavity volumes is effectively solved, and the classification of rigor grade is facilitated. Taking account variety of requirements and possibilities, the $\tau_{\text {Hemin }}$ in fixed scheme initial test is divided into three classes: $2000 \mathrm{~d}$, 200d and 20d.

Taking $\tau_{\mathrm{He}}$ as the main variable and $\tau_{\mathrm{Hemin}}$ as the basic criterion, not only the measurement leakage rate criterion for fixed scheme of helium mass spectrometry fine-leak test [22, $23,25]$ is designed, but also the formula for measuring leak rate criterion of multiple helium mass spectrometer fine-leak test is given $[26,27]$. 


\section{Quantitatively Determining the Maximum Detection-waiting Time}

Set the helium exchange time constant of gross-leak corresponding to the detectable minimum equivalent standard leak rate $\mathrm{L}_{0}$
For the pressing helium method and $\tau_{\mathrm{Hemin}}>\tau_{\mathrm{He} 0 \text {, when the }}$ measured leak rate at $\tau_{\mathrm{He}}=\tau_{\mathrm{He} 0}$ equals to the measured leak rate at $\tau_{\mathrm{He}}=\tau_{\mathrm{Hemin}}$, the time $\mathrm{t}_{2}$ is $\mathrm{t}_{2 \max }$. When $\mathrm{t}_{2} \leq \mathrm{t}_{2 \max }$, all the leak of the components under test with $\tau_{\mathrm{He} 0} \leq \tau_{\mathrm{He}} \leq \tau_{\mathrm{Hemin}}$ will be detected. Let's solve the equation as below:

$$
\begin{aligned}
& \tau_{H e 0}=\frac{V P_{0}}{L_{0}} \sqrt{\frac{M_{H e}}{M_{A}}} \\
& \frac{V P_{E}}{\tau_{H e \text { min }}}\left[1-\exp \left(-\frac{t_{1}}{\tau_{H e \text { min }}}\right)\right] \exp \left(-\frac{t_{2 \max }}{\tau_{H e \text { min }}}\right)=\frac{V P_{E}}{\tau_{H e 0}}\left[1-\exp \left(-\frac{t_{1}}{\tau_{H e}}\right)\right] \exp \left(-\frac{t_{2 \max }}{\tau_{H e 0}}\right) \\
& \frac{\tau_{H e \text { min }}}{\tau_{H e 0}}=\frac{\left[1-\exp \left(-\frac{t_{1}}{\tau_{H e \min }}\right)\right] \exp \left(-\frac{t_{2 \max }}{\tau_{H e \min }}\right)}{\left[1-\exp \left(-\frac{t_{1}}{\tau_{H e}}\right)\right] \exp \left(-\frac{t_{2 \max }}{\tau_{H e}}\right)}=\frac{\left[1-\exp \left(-\frac{t_{1}}{\tau_{H e \min }}\right)\right]}{1-\exp \left(-\frac{t_{1}}{\tau_{H e}}\right)} \exp \left[t_{2 \max }\left(\frac{\tau_{H e \min }-\tau_{H e 0}}{\tau_{H e \min } \tau_{H e 0}}\right)\right] \\
& t_{2 \max }=\frac{\tau_{H e \min } \tau_{H e 0}}{\tau_{H e \min }-\tau_{H e 0}}\left\{\ln \frac{\tau_{H e \min }}{\tau_{H e 0}}+\ln \left[\frac{1-\exp \left(-\frac{t_{1}}{\tau_{H e 0}}\right)}{1-\exp \left(-\frac{t_{1}}{\tau_{H e \min }}\right)}\right]\right\}
\end{aligned}
$$

In order to control the test deviation of $\tau_{\text {Hemin }}$ caused by $t_{2 \max }$ does not exceed $10 \%$, for the fixed scheme $t_{2 \max }$ is taken simultaneously

$$
t_{2 \max } \leqslant \frac{1}{10} \tau_{H e \min }
$$

Similarly, for the pre-filling helium method, when $\tau_{\mathrm{Hemin}}>\tau_{\mathrm{He} 0}$, the maximum detection-waiting time can be obtained by equation (11).

$$
t_{3 \max }=\frac{\tau_{H e \min } \tau_{H e 0}}{\tau_{H e \min }-\tau_{H e 0}} \ln \left(\frac{\tau_{H e \min }}{\tau_{H e 0}}\right)
$$

The fixed scheme $t_{3 \max }$ is taken simultaneously by equation (12).

$$
t_{3 \max } \leqslant \frac{1}{10} \tau_{H e \min }
$$

The above are the formulas for quantitative determination of the maximum detection-waiting time for helium mass spectrometry test method by using helium as a fine-leak tracer gas under the molecular flow theory model, given in literature $[22,23]$.

Usually $\mathrm{L}_{0}$ is already in transitional or mixed flow. Theoretical analysis and tests have proved that the existing of viscous flow component can significantly delay the helium leakage inside the component under test. The above formula has a safe margin and is reliable.

The quantitatively determined maximum detection-waiting, for most common range of the inner cavity volume, is significantly larger than the maximum detection-waiting time specified by the standard $[15,16]$. In order to fulfil length of time required for removing the absorbed helium when $\tau_{\mathrm{Hemin}}$ is bigger, the literature $[22,23]$ proposed a two-step test method and storage method.

Based on discussions above, the time for pressing helium in the multi-pressing helium method and the multi-pressing helium after prefilling helium method is given and verified in the literature $[26,27]$. The maximum detection-waiting time is quantitatively determined in the same literatures.

Using the above ideas in chapter 2 and chapter 3 , the literature $[28,29]$ studied internal gas mass spectrometric analyzing method for sealability test of components. When there is no helium gas inside the sealed components under test, the helium content method is selected to give the formula and criterion of the internal helium content after pressing helium, the shortest time of repeated pressing helium, the maximum detection-waiting time for internal gas mass spectrometry analyzing after pressing helium and the gross-leak test requirement. When there is no argon gas inside the sealed components under test, the argon content method is selected to give the formula and criterion of the internal argon content after storage or pressing argon, the required time for pressing argon, the maximum detection-waiting time and the gross-leak test requirement when $\mathrm{P}_{\text {Armax }} / \mathrm{P}_{0} \geq 11200 \mathrm{ppm}$. This method can be used for the identification test, cycle test and certification test of the destructive test when the available leak detector cannot meet the high rigor grade of test requirements. 


\section{Accumulative Helium Gross/Fine-leak Combination Test}

\subsection{Improvement of Combination Test Method by Using Helium as Gross-leak and Fine-leak Tracer Gas}

The Pernicka $700 \mathrm{H}$ cumulative helium mass spectrometer leak detector (CHLD) manufactured by Inficon uses advanced technologies such as Crgo pump, Prisma Quallrupol+Multiplier and cumulative testing. The temperature of the inner cavity of the cryogenic pump could be lowered to $20 \mathrm{~K}\left(-253^{\circ} \mathrm{C}\right)$, which effectively absorbs various gases other than hydrogen and helium. When the small chamber sealed by metal ring is used, the fine-leak rate $4 \times 10^{-9}$ $\mathrm{Pa} \cdot \mathrm{cm}^{3} / \mathrm{s}$ of helium gas can be detected effectively. The detector uses helium gas partial pressure $\mathrm{P}_{\mathrm{He} 0}$ presented in the air as gross leak tracer gas. Although both the instrument and the standard [16] stipulate that argon, oxygen, carbon dioxide and other gases could be used as the fine leak tracer gas, the sensitivity is not high and the test is unstable because fine leak gas may absorb these gases when passing through the cryogenic pump. In fact, this is a CHLD with helium as tracer gas for both fine-leak test and gross-leak test.

In the invention patent [30], the measured leak rate for gross-leak test $\mathrm{R}_{0 \max }$ is given.

$$
R_{0 \max }=L_{0} \frac{P_{H e 0}}{P_{0}} \sqrt{\frac{M_{A}}{M_{H e}}}
$$

Wherein, $\mathrm{P}_{\mathrm{He} 0}$ is the partial pressure of helium in normal air, $\mathrm{P}_{\mathrm{He} 0}=0.533 \mathrm{~Pa}$.

Take $\mathrm{R}_{0 \max }$ as $1.42 \times 10^{-5} \mathrm{~Pa} \cdot \mathrm{cm}^{3} / \mathrm{s}$ and $1.42 \times 10^{-4} \mathrm{~Pa} \cdot \mathrm{cm}^{3} / \mathrm{s}, \mathrm{L}_{0}$ is obtained from equation below as $1.0 \mathrm{~Pa} \cdot \mathrm{cm}^{3} / \mathrm{s}$ and $10 \mathrm{~Pa} \cdot \mathrm{cm}^{3} / \mathrm{s}$ respectively.

$$
L_{0}=R_{0 \max } \frac{P_{0}}{P_{H e 0}} \sqrt{\frac{M_{H e}}{M_{A}}}
$$

The $\tau_{\mathrm{He} 0}$, helium gas exchange time constant for gross leak test is obtained by equation below.

$$
\tau_{H e 0}=\frac{V P_{H e 0}}{R_{0 \max }}
$$

Applying the results of chapter 2 and 3, the method of accumulative helium gross- and fine-leak combination test is designed and improved.

In the helium mass spectrometry test by using helium as gross- and fine-leak tracer gas, it may be likely to judge a fine-leak component as gross-leak at the initial gross-leak test and impossible to accurately distinguish between gross and fine leaks. Since $\mathrm{P}_{\mathrm{He} 0}$ is only $0.533 \mathrm{~Pa}$, the literature $[13,19]$ and several component batches tested with Inficon indicate that it is difficult to take $\mathrm{R}_{0 \text { max }}$ as small as $5 \times 10^{-5} \mathrm{~Pa} \cdot \mathrm{cm}^{3} / \mathrm{s}$. In general, $\mathrm{R}_{0 \max }$ is taken as $1 \times 10^{-4} \mathrm{~Pa} \cdot \mathrm{cm}^{3} / \mathrm{s}$ for small chamber sealed with metal ring; $1 \times 10^{-3} \mathrm{~Pa} \cdot \mathrm{cm}^{3} / \mathrm{s}$ and $1 \times 10^{-2} \mathrm{~Pa} \cdot \mathrm{cm}^{3} / \mathrm{s}$ for medium and large chamber. Corresponding $\mathrm{L}_{0}$ is 7.07
$\mathrm{Pa} \cdot \mathrm{cm}^{3} / \mathrm{s}, 70.7 \mathrm{~Pa} \cdot \mathrm{cm}^{3} / \mathrm{s}$ and $707 \mathrm{~Pa} \cdot \mathrm{cm}^{3} / \mathrm{s}$ respectively, which is significantly larger than $1.0 \mathrm{~Pa} \cdot \mathrm{cm}^{3} / \mathrm{s}$ of the fluorocarbon bubble method. The maximum detection-waiting time determined by equation (9) (11) is significantly reduced and therefore difficult to guarantee enough time to remove absorbed helium. This is also the root cause of the serious detection missing in the gross-leak test, which can be seen from the literature $[18,31,32]$ and the analysis in the later chapter. Therefore, for the cumulative helium mass spectrometry combination test method, including its improvement in patent [30], the applicable range of $\tau_{\mathrm{Hemin}}$ and $\mathrm{V}$ is severely limited [31].

\subsection{A Method of Accumulative Helium Combination Test by Using Argon as Gross-leak Tracer Gas}

Both argon and helium are inert gases. In the normal air, the helium partial pressure $\mathrm{P}_{\mathrm{He} 0}$ is $0.533 \mathrm{~Pa}$ and the argon partial pressure $\mathrm{P}_{\mathrm{Ar} 0}$ is $946 \mathrm{~Pa}$ which is 1775 times of the helium's. According to the molecular flow model of gas exchange, if the argon and helium gas pressures inside the components are $\mathrm{P}_{\mathrm{Ar} 0}$ and $\mathrm{P}_{\mathrm{He} 0}$ respectively, under vacuum condition, for the same leak hole, the ratio of argon gas leak rate $R_{\mathrm{Ar} 0}$ to helium gas leak rate $R_{0}$ is

$$
\frac{R_{A r 0}}{R_{0}}=\frac{R_{A r 0}}{P_{H e 0}} \sqrt{\frac{M_{H e}}{M_{A r}}}=562
$$

Wherein, $\mathrm{M}_{\mathrm{Ar}}$ is $39.94 \mathrm{~g}$ which is the molar mass of argon expressed in grams.

In the cumulative helium mass spectrometry combination test, using argon as gross-leak tracer gas has higher sensitivity than helium. Tests, using Pernicka Model 700H CHLD with Inficon's Mr. Ruid Widt's self-made argon standard leaks holes, have shown that argon leak rate of $3.0 \times 10^{-2} \mathrm{~Pa} \cdot \mathrm{cm}^{3} / \mathrm{s}$ and $2.0 \times 10^{-3} \mathrm{~Pa} \cdot \mathrm{cm}^{3} / \mathrm{s}$ could be measured rather accurate through leaked argon went through the cryogenic pump unreasonably and argon absorption caused the accumulation curve to fall which lead to significant deviation.

Assuming $\mathrm{R}_{\mathrm{A} 0 \max }$ is $7.95 \times 10^{-4} \mathrm{~Pa} \cdot \mathrm{cm}^{3} / \mathrm{s}, 2.39 \times 10^{-3} \mathrm{~Pa} \cdot \mathrm{cm}^{3} / \mathrm{s}$ and $7.95 \times 10^{-3} \mathrm{~Pa} \cdot \mathrm{cm}^{3} / \mathrm{s}$ for different chamber volume ranges of the tested objects, there exists

$$
L_{0}=R_{A r 0 \max } \frac{P_{0}}{P_{A r 0}} \sqrt{\frac{M_{A r}}{M_{A}}}
$$

$\mathrm{L}_{0}$ is $0.1 \mathrm{~Pa} \cdot \mathrm{cm}^{3} / \mathrm{s}, \quad 0.3 \mathrm{~Pa} \cdot \mathrm{cm}^{3} / \mathrm{s}$ and $1.0 \quad \mathrm{~Pa} \cdot \mathrm{cm}^{3} / \mathrm{s}$, respectively. The initial fine-leak test adopts the more sensitive prefilling helium argon method, let prefilling helium ratio $\mathrm{k}$ of the fixed scheme be 0.21 , and the invention patent [33] is designed.

The $\mathrm{P}_{\mathrm{Ar} 0}$ in the normal air inside the component under test is taking as the gross-leak tracer gas, and the pre-filling or pressing helium as the fine-leak tracer gas. This makes accurate distinguish between the gross-leak and the fine-leak. The fine-leak measured leak rate criterion $R_{\max }$ may be less than or equal to $R_{0 \max }$, the relative gross-leak measured leak rate $R_{\text {Ar0max }}$, $R_{\max }$ may also be greater than $R_{0 \max }$. 


$$
\begin{gathered}
R_{0 \max }=R_{A r 0 \max } \frac{P_{H e 0}}{P_{A r 0}} \sqrt{\frac{M_{A r}}{M_{H e}}} \\
\tau_{H e 0}=\frac{V P_{A r 0}}{R_{A r 0 \max }} \sqrt{\frac{M_{H e}}{M_{A r}}}
\end{gathered}
$$

The argon exchange time constant of gross-leak:

$$
\tau_{A r 0}=\frac{V P_{A r 0}}{R_{A r 0 \max }}=\frac{V P_{0}}{L_{0}} \sqrt{\frac{M_{A r}}{M_{A}}}=\tau_{H e 0} \sqrt{\frac{M_{A r}}{M_{H e}}}
$$

Please note that the $\tau_{\mathrm{Ar} 0}$ in equation (5) in [31] is incorrect. The author of [31] apologizes for it.

In this case, $\tau_{\mathrm{He} 0}$ is much larger than $\tau_{\mathrm{He} 0}$ in cumulative helium mass spectrometry combination test method by using helium as gross-leak tracer gas, by which the maximum detection-waiting time for fine-leak test may be doubled or increased by an order of magnitude, and can be applied to a wider range of $\tau_{\mathrm{Hemin}}$ and $\mathrm{V}$.
In order to apply the cumulative helium mass spectrometry combination test by using argon as gross-leak tracer gas and helium as fine-leak tracer gas, the CHLD needs a series of enhancements. Please refer the literature [31, 33] for the details.

\section{Methods for Reducing and Preventing Gross-leak Detection Missing in Combination Test}

\subsection{Reducing Gross-leak Detection Missing in Combination Test by Using Helium as Tracer Gas}

As illustrated in the literature [34], for the first pressuring helium method, if the gross-leak detection time $t_{4}$ is from the start of ventilation, flushing and vacuuming of the chamber to the reading of the gross-leak rate after the components are placed in the chamber, the measured leak rate $R_{1}$ would be obtained by equation (20)

$$
R_{1}=\frac{V}{\tau_{H e}}\left\{P_{E}\left[1-\exp \left(-\frac{t_{1}}{\tau_{H e}}\right)\right] \exp \left(-\frac{t_{2}}{\tau_{H e}}\right)+P_{H e 0}\right\} \exp \left(-\frac{t_{4}}{\tau_{H e}}\right)
$$

A series typical relationship of $\mathrm{R}_{1} \sim \tau_{\mathrm{He}}$ is shown in figure 1 .

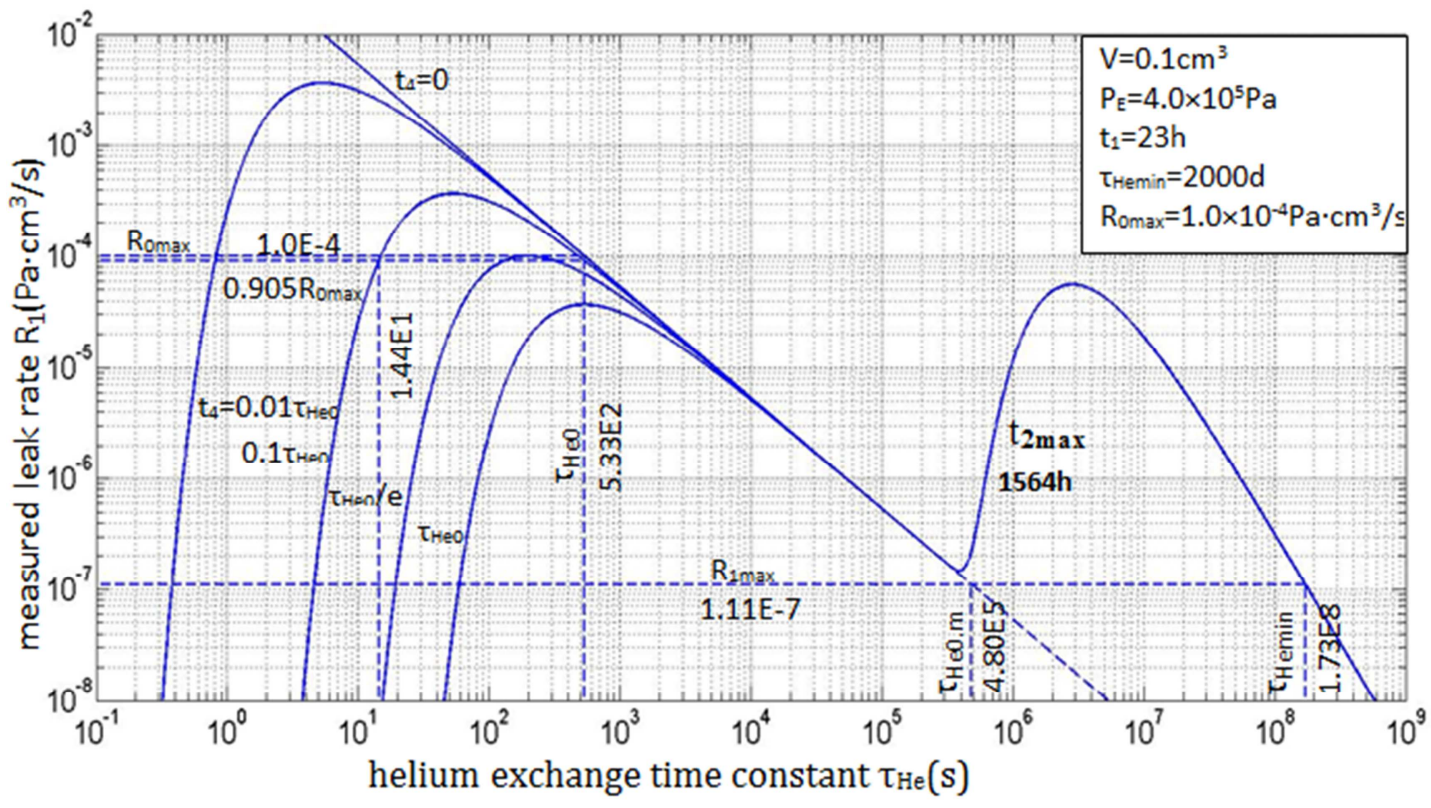

Figure 1. $R_{I} \sim_{\text {te }}$ typical relationship curve of helium mass spectrometry gross-leak test by pressuring helium method.

As seen from figure 1, under the condition that the inner helium partial pressure $\mathrm{P}_{\mathrm{He}}$ is no less than $\mathrm{P}_{\mathrm{He} 0}$ and the range of $\mathrm{t}_{4}$ is no more than $\tau_{\mathrm{He} 0} / \mathrm{e}$, the wider gross leak test range can be ensured without detection missing when the value of $t_{4}$ is reduced. Considering the feasibility, take the maximum gross-leak detection time $\mathrm{t}_{4 \max }$ in equation (21) as:

$$
\mathrm{t}_{4 \max }=0.1 \tau_{\mathrm{He} 0}
$$

As seen from figure 1 and similar drawings, $R_{1}$ is no less than $0.905 \mathrm{R}_{0 \max }$ in the range of $\tau_{\mathrm{He}}$ from $\tau_{\mathrm{He} 0}$ to $2.7 \times 10^{-2} \tau_{\mathrm{He} 0}$. It means that, based on the molecular flow theory, detection missing could be eliminated in the gross leak test while $\mathrm{L}$ is in the range of $\mathrm{L}_{0}$ to $37.0 \mathrm{~L}_{0}$. The range of $\mathrm{L}$ could be even larger if considering $\mathrm{L}$ around this rang is often in transitional flow or viscous flow state.

The same result also applies to the first prefilling helium method, the repeated test of multi-pressing helium method and pressing helium after prefilling helium method. 


\subsection{Reducing Gross-leak Detection Missing in Combination Test by Using Argon as Gross-leak Tracer Gas}

According to the literature [31, 34], when the argon gas with the partial pressure equal to $\mathrm{P}_{\mathrm{Ar} 0}$ is the gross-leak tracer gas of the cumulative helium mass spectrometry combination test method, the measured argon leak rate is obtained by equation (22) for various gross-leak detection time $t_{4}$.

$$
R_{A r}=\frac{V}{\tau_{A r}} P_{A r 0} \exp \left(-\frac{t_{4}}{\tau_{A r}}\right)
$$

The relationship between $\mathrm{R}_{\mathrm{Ar}}$ and $\tau_{\mathrm{Ar}}$ at various $t_{4}$ is shown in figure 2.

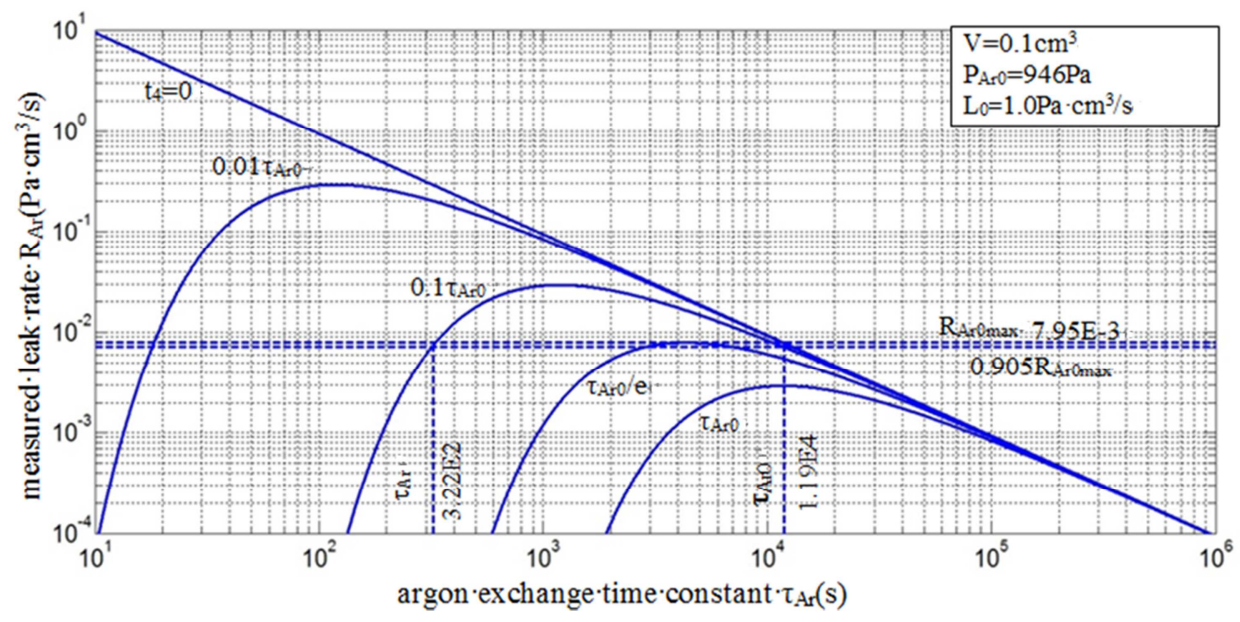

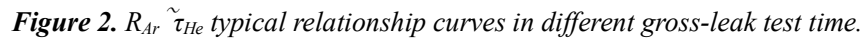

As seen in figure 2, the maximum detection time of gross-leak test is

$$
\mathrm{t}_{4 \max }=0.1 \tau_{\mathrm{Ar} 0}
$$

With the criterion of $0.905 \mathrm{R}_{\mathrm{Ar} 0 \max }$, the detection missing of gross-leak can be prevented when $\tau_{\mathrm{Ar}}$ in the range of $\tau_{\mathrm{Ar} 0} \sim 2.7 \times 10^{-2} \tau_{\mathrm{Ar} 0}$ or $\mathrm{L}$ in $\mathrm{L}_{0} \sim 37.0 \mathrm{~L}_{0}$.

\subsection{Maintaining $P_{\mathrm{HeO}}$ and $\boldsymbol{P}_{\mathrm{ArO}}$ Inside the Components Under Test}

As seen from equation (20) and figure 1, before the helium mass spectrometry combination test by using helium as gross-leak tracer gas, the internal $\mathrm{P}_{\mathrm{He}}$ should be maintained no less than $\mathrm{P}_{\mathrm{He} 0}$. It can be seen from equation (22) and figure 2 that the internal $\mathrm{P}_{\mathrm{Ar}}$ should be no less than $\mathrm{P}_{\mathrm{Ar} 0}$ before the accumulation combination test by using argon as gross-leak tracer gas. The component under test should be kept in normal dry air with normal helium and argon partial pressure when removing the surface absorption.

If the components under test placed under the condition lack of normal helium and argon partial pressure of the air for the time $\Delta t$ during the test under vacuum condition or removal of the surface absorption, the components should be kept in normal air for the time of $3.23 \Delta t$ to recover the inner helium partial pressure to no less than $0.9 \mathrm{P}_{\mathrm{He} 0}$ and the inner argon partial pressure to no less than $0.9 \mathrm{P}_{\mathrm{Ar} 0}$. Please refer to literature [32] part 3 for details. After that, the criterion for gross-leak test should be $0.9 \mathrm{R}_{0 \max }$ or $0.9 \mathrm{R}_{\mathrm{Ar} 0 \max }$. In order to reduce the detection missing in gross-leak test, during the maximum gross-leak detection time $t_{4 \max }$, the criterion for gross-leak test shall be $0.81 \mathrm{R}_{0 \max }$ or $0.81 \mathrm{R}_{\mathrm{Ar} 0 \max }$, which is also effective in repeated test in the accumulative helium mass spectrometry combination test.

\subsection{Supplement Test for Larger Gross-leak}

As shown in figure 1 and figure 2, the cumulative helium mass spectrometry combination test with helium or argon as the gross-leak tracer gas can reduce but not completely prevent the gross-leak detection missing. Let's assume there is a large leak hole in a component which has not been completely sealed. If it has been put into the chamber, after ventilation, flushing and vacuuming, the internal $\mathrm{P}_{\mathrm{He}}$ or $\mathrm{P}_{\mathrm{Ar}}$ would be zero before the gross-leak rate detection. Therefore, the gross-leak may not be detected.

It is noticed that the improved differential pressure leak test might be a relatively feasible method. Differential pressure leak test is mainly used to detect components with standard shape, such as crystal oscillators. The instrument has a chamber for the component under test and a reference chamber for the solid parts with the same appearance as the component under test. The volume $\mathrm{V}_{0}$ which denotes the space between the chamber and the solid parts should be much less than the volume $\mathrm{V}$ which denotes the inner cavity of the component under test. Each channel could only be used for testing components with a certain appearance. The large leakage is detected by comparing the pressure in two chambers. Utilizing the sensitivity of the instrument's differential pressure meter, assuming $\mathrm{V}_{0}$ could be amplified to several times or dozen times of $\mathrm{V}$ and instrument is only used to detect larger gross-leak of $\mathrm{L}>37.0 \mathrm{~L}_{0}$, a single channel of the instrument can be used to detect the larger gross-leak of components with a certain inner cavity volume $\mathrm{V}$ range. This can prevent detection missing in gross-leak test.

The idea still needs to be further studied and proved. 


\section{Preventing Detection Missing in Helium Mass Spectrometric Fine-leak Test}

\subsection{Quantitative Expansion of the Maximum Detection-waiting Time for Helium Mass Spectrometry Fine-leak Test}

As illustrated in figure 1, when the criterion of fine-leak test $\mathrm{R}_{1 \max }$ is less than that of gross-leak $\mathrm{R}_{0 \max }$, the maximum detection-waiting time can be further extended for cumulative helium mass spectrometer fine-leak test of pressing helium method.

Take the middle-leak time constant

$$
\tau_{H e 0 . m}=\tau_{H e 0} \frac{R_{0 \max }}{R_{1 \max }}
$$

In pressing helium method, when measured leak rate at $\tau_{\mathrm{He}}=\tau_{\mathrm{He} 0 \mathrm{~m}}$ equals the leak rate criterion $\mathrm{R}_{1 \max }$ at $\tau_{\mathrm{He}}=\tau_{\mathrm{Hemin}}$, the time $t_{2}$ is the quantitatively expended maximum detection-waiting time $t_{2 \max }$. By the similar deduction as described in chapter 3 , the following equation is obtained:

$$
t_{2 \max }=\frac{\tau_{H e \min } \tau_{H e 0 . m}}{\tau_{H e \text { min }}-\tau_{H e 0 . m}}\left\{\ln \left(\frac{\tau_{H e \min }}{\tau_{H e 0 . m}}\right)+\ln \left[\frac{1-\exp \left(-\frac{t_{1}}{\tau_{H e 0 . m}}\right)}{1-\exp \left(-\frac{t_{1}}{\tau_{H e \text { min }}}\right)}\right]\right\}
$$

Or under condition of $t_{2} \leqslant \frac{1}{10} \tau_{H e \min }$, let $\mathrm{t}_{2 \max }$ be

$$
t_{2 \max }=\frac{\tau_{H e \min }^{2} P_{H e 0}}{P_{E} t_{1}-P_{H e 0} \tau_{H e \min }}\left\{\ln \left(\frac{P_{E} t_{1}}{P_{H e 0} \tau_{H e \min }}\right)+\ln \left[\frac{1-\exp \left(-\frac{P_{E} t_{1}^{2}}{P_{H e 0} \tau_{H e \min }{ }^{2}}\right)}{1-\exp \left(-\frac{t_{1}}{\tau_{H e \min }}\right)}\right]\right\}
$$

Where $t_{2 \max } \leq \frac{1}{10} \tau_{\text {Hemin }}$

Equation (25) and (26) are also applicable to cumulative helium mass spectrometry combination test by using argon as gross-leak tracer gas and helium as fine-leak tracer gas when using pressing helium-argon after prefilling argon method.

Similarly, for prefilling helium cumulative helium mass spectrometry fine-leak test, and for fine-leak test in prefilling helium and argon cumulative helium mass spectrometry combination test using argon as gross-leak test tracer gas and helium as fine-leak test tracer gas, when criterion $\mathrm{R}_{2 \max }$ for fine-leak test becomes less than the criterion $R_{0 \max }$ of gross-leak test, take the middle-leak time constant

$$
\tau_{H e 0 . m}=\tau_{H e 0} \frac{R_{0 \max }}{R_{2 \max }}
$$

For multiple accumulation helium mass spectrometry combined test and accumulation helium mass spectrometry combined test by using argon as gross-leak tracer gas and helium as fine-leak tracer gas, the equation has been got of quantitative expended maximum detection-waiting time through taking the relative middle-leak time constant $\tau_{\mathrm{He} 0 \mathrm{~m}}$ [32]. It has proved through both graphical and analytic method that all these equations are applicable as long as internal $\mathrm{P}_{\mathrm{He}}$ is no less than $0.9 \mathrm{P}_{\mathrm{He} 0}$ and $\mathrm{P}_{\mathrm{Ar}}$ no less than $0.9 \mathrm{P}_{\mathrm{Ar} 0}$.

For the first time or multiple times test of helium mass spectrometry fine-leak test, as long as $\mathrm{R}_{\max }$ is less than $\mathrm{L}_{0}$ 's corresponding $\mathrm{R}_{0 \max }$, if after prefilling helium or pressing helium, the checked part has been stored in the normal air environment or internal $\mathrm{P}_{\mathrm{He}}$ no less than $0.9 \mathrm{P}_{\mathrm{He} 0}$ as described in chapter 5.3, the above formulas for quantitative expended maximum detection waiting time are applicable.

Calculations according to these equations indicate, after quantitative expended maximum detection-waiting time, for different rigor grade, the maximum detection-waiting time could be longer than that determined quantitatively by several times or even 1 to 2 order of magnitudes and it could be applied for wider range of inner cavity. In general, large $\tau_{\text {Hemin, }}$ small $\mathrm{V}$, small leak rate criterion $\mathrm{R}_{\max }$ and longer expended maximum detection-waiting time, those together perfectly match the requirement of longer time needed by removing the absorbed helium. There is no need to employ the two-step method and storage method described in chapter 3 in this circumstance any more.

\subsection{The Utilization of Viscous Flow Component to Prevent Detection Missing of Fine-leak Test}

\subsubsection{Duty Ratio of Viscous Flow $l_{\text {He.n }}$}

Components, whose $\tau_{\mathrm{He}}$ equals to or is slightly less than $\tau_{\mathrm{He} 0}$, are most likely to be missed during fine-leak test. As mentioned earlier, when fluorochemicals bubble method is used for gross-leak test, in helium mass spectrometry fine-leak test, take $\mathrm{L}_{0}=1.0 \mathrm{~Pa} \cdot \mathrm{cm}^{3} / \mathrm{s}$; and $\mathrm{L}_{0}=7.07$ to $707 \mathrm{~Pa} \cdot \mathrm{cm}^{3} / \mathrm{s}$ for accumulated helium mass spectrometry combination test. When argon is used as gross-leak tracer gas in gross-leak test, take $\mathrm{L}_{0}=0.1$ to $3 \mathrm{~Pa} \cdot \mathrm{cm}^{3} / \mathrm{s}$. According to literature [3, 35-38], it can be considered that the range of $\mathrm{L}_{0}$ above is the state of 
transition flow. To further avoid the detection missing of fine-leak test, considering the effect of viscous flow during pressing helium and storage, the success rate of fine-leak test can be improved by controlling the pressure of helium and storage time.

According to the antecedent literature, under the standard condition, the pressure at each end of a leak hole is $1.0 \mathrm{P} 0$ and 0 respectively. When $\mathrm{L}_{0}=1.0 \mathrm{~Pa} \cdot \mathrm{cm}^{3} / \mathrm{s}$, the duty ratio $l_{\mathrm{He.n}}$ of viscous flow to the whole helium flow is $1_{\mathrm{He} . \mathrm{n}}=0.50$. From figure 3.3 and 3.4 in literature [3], it can be seen that in a double logarithmic coordinate system, $1_{\mathrm{He.n}}$ has a positive linear relationship with stand helium leak rate L. Taking a leak hole whose sectional area has length-width ratio of 10:1 as example, the calculated slope is 0.314 , so that there exist:

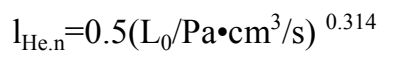

From equation (28), $\mathrm{l}_{\mathrm{He} . \mathrm{n}}$ under various $\mathrm{L}_{0}$ and $\mathrm{L}_{\mathrm{He} 0}$ is shown in table 2.

Table 2. Viscous flow duty ratio $l_{H e . n}$ under standard condition with different $L_{0}$, $L_{\mathrm{HeO}}$.

\begin{tabular}{lllll}
\hline $\mathrm{L}_{0}\left(\mathrm{~Pa} \cdot \mathrm{cm}^{3} / \mathrm{s}\right)$ & 3.0 & 1.0 & 0.3 & 0.1 \\
$\mathrm{~L}_{\mathrm{He} 0}\left(\mathrm{~Pa} \cdot \mathrm{cm}^{3} / \mathrm{s}\right)$ & 8.07 & 2.69 & 0.807 & 0.269 \\
$\mathrm{l}_{\mathrm{He.n}}$ & 0.706 & 0.500 & 0.343 & 0.243 \\
$\mathrm{P}_{\mathrm{Emin}} / \mathrm{P}_{0}$ & 1.72 & 1.77 & 1.84 & 1.93 \\
$\mathrm{~T}_{3 \min } / \tau_{\mathrm{He} 0}$ & 0.124 & 0.167 & 0.226 & 0.292 \\
\hline
\end{tabular}

\subsubsection{Minimize Pressure of Helium $P_{\text {Emin }}$ in Pressing Helium Method}

For initial test of pressing helium method or pressing helium-argon after prefilling argon method, and for multiple tests, during sealing process the prefilled gas pressure and inner gas pressure before pressing is generally $(1+10 \%) \mathrm{P}_{0}$. When pressing helium after sealing, internal helium pressed by viscous flow component is proportional to $\frac{1}{2}\left(P_{E}^{2}-P_{0}^{2}\right)$.

Appropriately raising $\mathrm{P}_{\mathrm{E}}$ may make the helium pressure equal or greater than the 1.1 times pressure that of helium pressed completely by molecular flow pressure. This pressure may be taken as the safe margin to prevent detection missing of fine-leak test.

Refer to [38], in order to achieve the 1.1 times pressure, the followings should be satisfied:

$$
\begin{gathered}
P_{E}\left(1-l_{H e . n}\right) \frac{L_{H e 0}}{P_{0}}+\frac{\left(P_{E}^{2}-P_{0}^{2}\right) / 2}{P_{0} / 2} l_{H e . n} \frac{L_{H e 0}}{P_{0}}=1.1 P_{E} \frac{L_{H e 0}}{P_{0}} \\
l_{H e . n} P_{E}^{2}-\left(0.1+l_{H e .0}\right) P_{0} P_{E}-l_{H e . n} P_{0}^{2}=0
\end{gathered}
$$

The effective solution is obtained:

$$
P_{E \min }=P_{0}\left(\frac{1}{2}+\frac{1}{20 l_{H e . n}}+\sqrt{\left(\frac{1}{2}+\frac{1}{20 l_{H e . n}}\right)^{2}+1}\right)
$$

From equation (29), the required value of $\mathrm{P}_{\mathrm{Emin}} / \mathrm{P}_{0}$ corresponding to various $\mathrm{L}_{0}$ and $\mathrm{L}_{\mathrm{He} 0}$ is obtained. See table 2 for details.
Observing $\mathrm{P}_{\text {Emin }} / \mathrm{P}_{0}$ values in table 2 , it may be noticed that the minimum helium pressure $\mathrm{P}_{\mathrm{Emin}}$ can be safely taken as $2 \mathrm{P}_{0}$ when $\mathrm{L}_{0} \geq 0.1 \mathrm{~Pa} \cdot \mathrm{cm}^{3} / \mathrm{s}$, including $\mathrm{L}_{0}>3 \mathrm{~Pa} \cdot \mathrm{cm}^{3} / \mathrm{s}$. The derivation here verifies the provisions in many standards specifying that the helium pressure is not less than $2 \mathrm{P}_{0}$, that is different from certain standard specifying that helium pressure not less than $\mathrm{P}_{0}$.

\subsubsection{The Minimum Detection-waiting Time $t_{3 \min }$ for Prefilling Helium Method}

Let the minimum detection-waiting time $\mathrm{t}_{3 \min }<0.3 \tau_{\mathrm{He} 0}$, the internal helium pressure of checked part having $\tau_{\mathrm{He}}=\tau_{\mathrm{He} 0}$ can be linearly calculated approximately. Regardless of viscous flow and considering only molecular flow, the time constant $\tau_{\mathrm{He} . \mathrm{f}}$ is

$$
\tau_{H e . f}=\tau_{H e 0} \frac{1}{1-l_{H e . n}}
$$

When the internal pressure equals to or is slightly greater than $\mathrm{P}_{0}$ and checked part placed in the air having the pressure of $\mathrm{P}_{0}$, the viscous flow component of a checked part has almost no leak. When reached $t_{3 \min }$, to ensure the internal helium pressure comply with the 1.1 times molecular flow pressure, the following should be satisfied:

$$
\begin{gathered}
1-\frac{t_{3 \min }}{\tau_{H e . f}}=1.1\left(1-\frac{t_{3 \min }}{\tau_{H e 0}}\right) \\
1-\frac{t_{3 \min }}{\tau_{H e 0}}\left(1-l_{H e . n}\right)=1.1\left(1-\frac{t_{3 \min }}{\tau_{H e 0}}\right) \\
t_{3 \min }=\tau_{H e 0} \frac{1}{1+10 l_{H e . n}}
\end{gathered}
$$

Table 2 shows $t_{3 \min } / \tau_{\mathrm{He} 0}$ calculated by equation (31) for various $\mathrm{L}_{0}, \mathrm{~L}_{\mathrm{He} 0}$. The $\mathrm{t}_{3 \min } / \tau_{\mathrm{He} 0}$ values are smaller than 0.3 , which verifies the earlier assumptions. The following should be satisfied simutaneously to ensure enough time for fine-leak test:

$$
t_{3 \min } \leq \frac{1}{3} t_{3 \max } \text { or } t_{3 \max }-t_{3 \min } \geq 24 h
$$

Thus the 1.1 times safe margin is satisfied by adding positive deviation of prefilling pressure and $t_{3 \min }$ for prefilling helium method.

\subsection{The Maximum Detection-waiting Time $t_{5 \max }$ When $\boldsymbol{R}_{\max }$ No Less than $R_{0 \max }$}

The $t_{5}$ denotes fine-leak detection time. It is defined as, after putting the checked part into a test chamber, the time starting from ventilating, flushing and vacuuming the chamber to the time when data of fine-leak test is taken. During this period cumulative helium mass spectrometry gross-leak test might be carried out.

In cumulated helium mass spectrometry combination test, 
fine-leak test criterion $\mathrm{R}_{\max }$ should be smaller than $\mathrm{R}_{0 \max }$. Only in helium mass spectrometry fine-leak test and fine-leak test of combination test by argon gross-leak and helium fine-leak, $\mathrm{R}_{\max }$ is not smaller than $\mathrm{R}_{0 \max }$. The internal existing pressure $\mathrm{P}_{\mathrm{He} 0}$ is not taken into consideration during quantitatively determining maximum detection-waiting time. When the checked parts first detected by pressing helium or pressing helium argon method, the detection leak rate at $t_{5}$ is

$$
\begin{gathered}
R_{1}=\frac{V P_{E}}{\tau_{H e}}\left[1-\exp \left(1-\frac{t_{1}}{\tau_{H e}}\right)\right] \exp \left(-\frac{t_{2}}{\tau_{H e}}\right) \exp \left(-\frac{t_{5}}{\tau_{H e}}\right) \\
R_{1}=\frac{V P_{E}}{\tau_{H e}}\left[1-\exp \left(1-\frac{t_{1}}{\tau_{H e}}\right)\right] \exp \left(-\frac{t_{2}+t_{5}}{\tau_{H e}}\right)
\end{gathered}
$$

As the result, the detection missing in fine-leak test will not occur as long as $t_{2}+t_{5} \leq t_{2 \max }$. When $t_{2 \max }-t_{2} \leq 0.1 \tau_{\text {He } 0}$, take

$$
t_{5 \max }=0.1 \tau_{H e 0}=0.1 \frac{V P_{0}}{L_{0}} \sqrt{\frac{M_{H e}}{M_{A}}}
$$

The 1.1 times helium pressure safe margin described in 6.2 also prevents the detection missing in fine-leak test.

Similarly, for the initial test by prefilling helium or helium argon method, and for multiple test, so long as the actual detection-waiting time $t_{2}$ plus fine-leak detection time $t_{5}$ does not exceed the quantitatively determined maximum detection-waiting time, or when the maximum detection-waiting time minus actual detection-waiting time is equal to or less than $0.1 \tau_{\mathrm{He} 0}$, and $t_{5}$ does not exceed $t_{5 \max }$ in equation (34), the detection missing of fine-leak test can be prevented.

As illustrated in [34], considering the possibility of improvement, for helium mass spectrometry fine leak test, at the same time let

$$
30 \mathrm{~s} \leq \mathrm{t}_{5 \max } \leq 300 \mathrm{~s}
$$

For the combination of argon gross-leak and helium fine-leak test, at the same time let

$$
60 \mathrm{~s} \leq \mathrm{t}_{5 \max } \leq 1200 \mathrm{~s}
$$

Moreover, on the premise that the pressing helium pressure $\mathrm{P}_{\mathrm{E}}$ is not less than $2 \mathrm{P}_{0}$, detection-waiting time is no less than $\mathrm{t}_{3 \min }$ after prefilling helium, for various applicable helium mass spectrometry fine-leak test, repeated test is allowed within the maximum detection-waiting time. Although for different detection-waiting time, the detection leak rate may differ largely but the fine-leak should be correctly detected.

\subsection{The Maximum Detection-waiting Time $t_{5 \max }$ When $\boldsymbol{R}_{\max }$ Less than $\boldsymbol{R}_{0 \max }$}

For the first helium mass spectrometry fine-leak test by pressing helium, fine-leak of the cumulated helium mass spectrometry combination test by pressing helium argon after prefilling argon under the condition of maintaining internal $\mathrm{P}_{\mathrm{He} 0}$ kept, the detection leak rate equation is

$$
R_{1}=\frac{V}{\tau_{H e}}\left\{P_{E}\left[1-\exp \left(-\frac{t_{1}}{\tau_{H e}}\right)\right] \exp \left(-\frac{t_{2}}{\tau_{H e}}\right)+P_{H e 0}\right\} \exp \left(-\frac{t_{5}}{\tau_{H e}}\right)
$$

Refer to equation (37) and figure 1, assuming replacing the gross-leak in the title of figure 1 to fine-leak, and replacing $t_{4}$ in figure 1 to $t_{5}, R_{1} \sim \tau_{\mathrm{He}}$ typical relationship for initial fine-leak test or multiple fine-leak tests are shown. The detection leak rate of the checked part having $\tau_{\mathrm{He}}=\tau_{\mathrm{He} 0}$ is $\mathrm{R}=\mathrm{R}_{0 \max }$ at the time of the maximum detection-waiting time $t_{\max }$ and $t_{5}=0$. After the maximum detection time $t_{5 \max }$ of fine-leak test, there should be

$$
\begin{gathered}
R_{0 \max } \exp \left(-\frac{t_{5 \max }}{\tau_{H e 0}}\right)=R_{\max } \\
t_{5 \max }=\tau_{H e 0} \ln \left(\frac{R_{0 \max }}{R_{\max }}\right)
\end{gathered}
$$

Both graphic and calculation prove that taking $\mathrm{t}_{5 \max }$ through equation (38), the detection missing of fine-leak test of the checked part having $\tau_{\mathrm{He} 0} \leq \tau_{\mathrm{He}} \leq \tau_{\mathrm{Hemin}}$ will not occur.

For helium mass spectrometry fine-leak test with fluorocarbon compound bubble gross-leak test method, there should be

$$
t_{5 \max }=\frac{V P_{0}}{L_{0}} \sqrt{\frac{M_{H e}}{M_{A}}} \ln \left(\frac{R_{0 \max }}{R_{\max }}\right)
$$

where $\mathrm{L}_{0}=1.0 \mathrm{~Pa} \cdot \mathrm{cm}^{3} / \mathrm{s}, \mathrm{R}_{0 \max }=1.42 \times 10^{-5} \mathrm{~Pa} \cdot \mathrm{cm}^{3} / \mathrm{s}$.

Refer to [34], considering possible improvement later, at the same time take

$$
30 \mathrm{~s} \leq \mathrm{t}_{5 \max } \leq 300 \mathrm{~s}
$$

For cumulative helium mass spectrometry combination test method using helium as leak trace gas, there exist

$$
t_{5 \max }=\frac{V P_{H e 0}}{R_{0 \max }} \ln \left(\frac{R_{0 \max }}{R_{\max }}\right)
$$

where

$$
60 \mathrm{~s} \leq \mathrm{t}_{5 \max } \leq 1200 \mathrm{~s}
$$

For cumulative helium mass spectrometry combination test with argon as gross-leak and helium as fine-leak trace gas, there exist 


$$
t_{5 \max }=\frac{V P_{A r 0}}{R_{A r 0 \max }} \sqrt{\frac{M_{H e}}{M_{A r}}} \ln \left(\frac{R_{0 \max }}{R_{\max }}\right)
$$

where

$$
60 \mathrm{~s} \leq \mathrm{t}_{5 \max } \leq 1200 \mathrm{~s}
$$

In equation (38), (39), (41) and (43), when the fine-leak criterion $\mathrm{R}_{\max }<\mathrm{R}_{0 \max }$ but $\mathrm{R}_{\max }$ is closing to $\mathrm{R}_{0 \max }$ and $\ln \left(\frac{R_{0 \max }}{R_{\max }}\right)$ is approaching $0, \mathrm{t}_{5 \max }$ might be less than the $\mathrm{t}_{5 \max }$ in equation (34), it can hardly meet the test requirement. To fix the problem, let equation (39) and (34) be equal

$$
\begin{gathered}
\frac{V P_{0}}{L_{0}} \sqrt{\frac{M_{H e}}{M_{A}}} \ln \left(\frac{R_{0 \max }}{R_{\max }}\right)=0.1 \frac{V P_{0}}{L_{0}} \sqrt{\frac{M_{H e}}{M_{A}}} \\
R_{\max }=0.905 R_{0 \max }
\end{gathered}
$$

It has been proved through both graphic and calculation that in the range of $R_{0 \max } \geq R_{\max } \geq 0.905 R_{0 \max }$, take $t_{5 \max }=0.1 \tau_{\text {He } 0}$, the detection missing in fine-leak will not appear. Therefore, the more accurate condition in the title of chapter 6.3 should be $R_{\max }$ no less than $0.905 R_{0 \max }$ and for chapter 6.4 should be $R_{\max }$ less than $0.905 \mathrm{R}_{0 \max }$.
When employing the method described in chapter 5.3, the internal pressure $\mathrm{P}_{\mathrm{He}}$ is not less than $0.9 \mathrm{P}_{\mathrm{He} 0}$. During the maximum fine-leak detection time $t_{5 \max }$, letting the fine-leak criterion be $0.9 \mathrm{R}_{\max }$, although the detection leak rate of multiple helium mass spectrometry fine-leak test within the maximum detection-waiting time may differ largely, the fine-leak can be accurately determined.

Part of the discussion in chapter 6.3 and 6.4 is the improvement of patents [34, 39]. In case of authorized employing the patents, please apply improvements stated in this article.

\section{Case Analysis}

\subsection{Leakage of Tracer Gas Can Explain Most of the Detection Missing and Non-detection Missing Phenomena}

The methods of reducing and preventing the detection missing in gross-leak test and fine-leak test in this paper and literature [34] were used to calculate and analyze the CHLD test case in literature [13, 14]. Three groups of miniature samples were used for testing. The test conditions and calculation results of maximum detection-waiting time and maximum gross-leak and fine-leak detection time are shown in table 3.

Table 3. Conditions and calculation results of CHLD in literature.

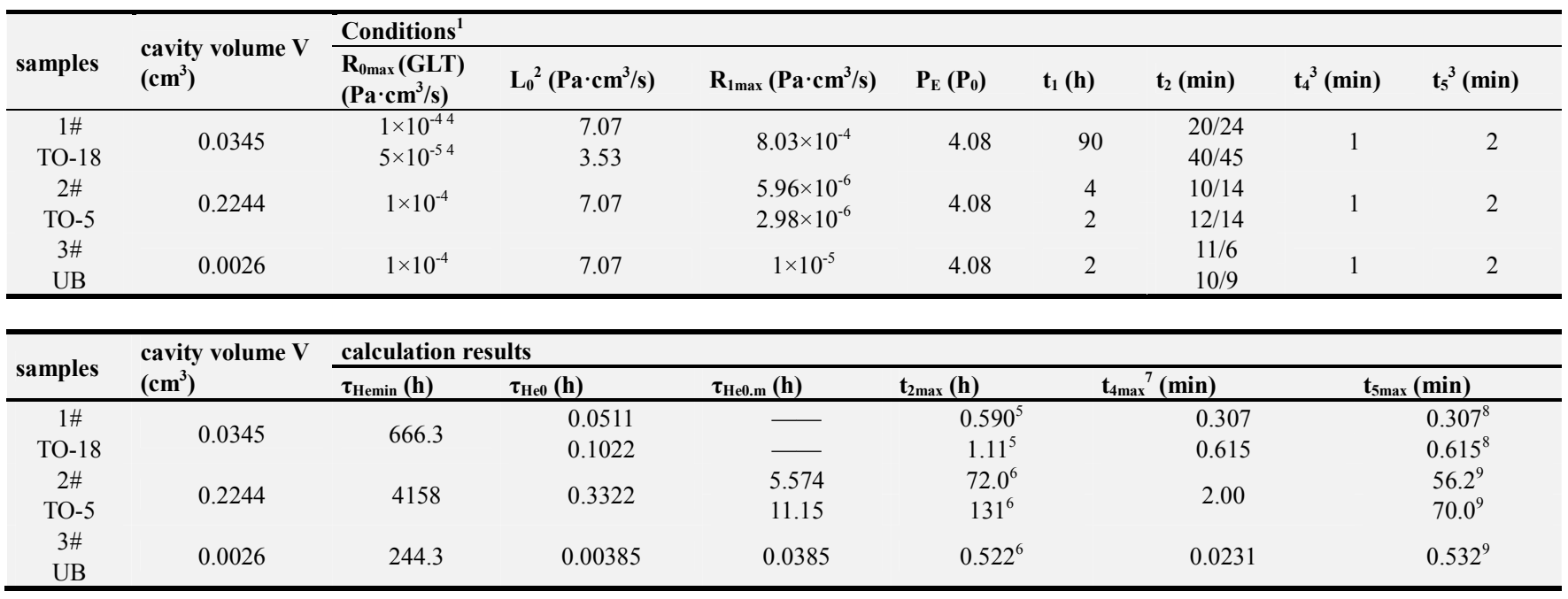

notes:

${ }^{1}$ the test conditions are mostly obtained from literature [14]32-page table;

${ }^{2}$ From $\mathrm{L}_{0}$ equation in chapter 4.1 ;

${ }^{3}$ Sets of $t_{4}, t_{5}$ data is not provided in literature [14], based on multiple tests on Pernicka $700 \mathrm{H}$, these are estimated by the authors;

${ }^{4}$ The $\mathrm{R}_{0 \max }$ is less than $\mathrm{R}_{1 \max }$, the setting is not adequate;

${ }^{5}$ Accroding to equation (9);

${ }^{6}$ Accroding to equation (26);

${ }^{7}$ Accroding to equation (21);

${ }^{8}$ Taking $\mathrm{t}_{5 \max }=\mathrm{t}_{4 \max }$;

${ }^{9}$ Accroding to equation (41).

In this example, all $\mathrm{P}_{\mathrm{E}}$ of the samples in three groups of CHLD combination test by pressing helium method were $4.08 \mathrm{P}_{0}$, larger than $\mathrm{P}_{\mathrm{Emin}}=2 \mathrm{P}_{0}$, and thus the detection missing did not occur.
By comparing the data of $t_{2}$ and $t_{2 \max }, t_{4}$ and $t_{4 \max }, t_{5}$ and $t_{5 \max }$ in table 3 , it shows that $t_{2}$ of each group is less than $t_{2 \max }$, and thus the detection missing will not happen due to the long maximum detection-waiting time. For T0-5 samples in group 
2 , $t_{4}$ is less than $t_{4 \max }$ and $t_{5}$ is far less than $t_{5 \max }$, so as shown in table 1 , in the CHLD combination test, the gross-leak and fine-leak detection missing did not happen to this group. For T0-18 samples in group $1, t_{4}$ is greater than $t_{4 \max }$ and $t_{5}$ is significantly greater than $t_{5 \max }$, so as shown in table 1 , excessive leakage of tracer gas in both $t_{4}$ and $t_{5}$ results in relatively high detection missing rate in the CHLD combination test. The time $t_{4}$ of UB sample in group 3 is much larger than $t_{4 \max }$ and $t_{5}$ is significantly larger than $t_{5 \max }$, so asshown in table 1, excessive leakage of tracer gas in the CHLD combination test of this group resulted in total detection missing in fine-leaktest. The above explanation of most of the non-leakage and leakage phenomena verifies the correctness and effectiveness of the methods to reduce and prevent leakage detection missing.

For the gross-leak sample of UB in group $3, t_{2}$ was also smaller than $t_{2 \max }, t_{4}$ was much larger than $t_{4 \max }$ and $t_{5}$ was larger than $t_{5 \max }$. However, no detection missing happened inthe gross-leak CHLD combination test. This phenomenen is unusual. It could be interpreted by two possibilities. One is relatedto absorbed helium. As in the experimental study [17], the initial adsorbed helium leak rate of the ceramic samples is high after pressing helium. The 5 ceramic samples indeed have larger gross-leak,. Within the time $t_{2}$ and $t_{4}$, the helium leakage rate inside the samples as indicated in table 3, attenuated to very low. According to the analysis of chapter 7.2 , if the leak hole of sample has been blocked, the leakage rate should close to zero. However the leakage caused by shell adsorbed heliumis still greater than the gross-leak criterion $\mathrm{R}_{0 \max }$. The other possibility is that the samples has large fine-leak. Often for Kr85 and CHLD combination test, many fine-leak components are judged as gross-leak. These 5 samples are judged as gross-leak, but actually they have relative larger fine-leak. The $t_{2}$ of the group samples is less than $t_{2 \max }$. As long as $R_{1}$ in equation (20) is greater than $R_{0 \max }$, most UB fine-leak samples would be observed as gross-leak in CHLD combination test. If one of the those explanations is true, all the detection missing and non-detection missing phenomena in the CHLD test in literature [13, 14] can be successfully explained by the leakage of tracer gas and the partial blockage analysis in chapter 7.2.

\subsection{Blockage Does Exist but Is Not the Main Cause of High Detection Missing Rates}

The three charts of internal gas analysis on pages 16, 18 and 19 in literature [14] indicates that after the intial test and repeated test, the oxygen content of samples exceeds $10 \%$, or the water vapor content exceeds $5000 \mathrm{ppm}$. Most of the samples have both phenomenas at the same time. The samples are leaking and their sealings are unqualified. The internal oxygen and water vaporof leaking samples are often related to each other. On page 19, there are 10 samples in group 1 . Among the 5 fine-leak ones and 3 gross-leak ones (a, c, d), the correlation coefficient of their internal water vapor content and oxygen content in the calculated value is 0.958 . It is quite regular, not like what it is in the abnormal phenomena where the leakage holes are blocked or changes caused by the leakage hole instability during the test process. Exceptions are gross-leak sample b and e, especially sample e which has the highest internal water vapor contentbut 0 oxygen content (or less than $0.1 \%$ ). This phenomenon could be explained so that sample e has large gross-leak, but the leak hole was blocked in combination test and therefore detection missing happened. After initial $\mathrm{Kr} 85$ vacuum test or a CHLD or Kr85 vacuum tests later, internal gas was evaporated which makes oxygen reached zero. At the beginning of nitrogen inflation, external and internal pressure difference $\mathrm{P}_{0}$ forms an inward viscous flow. Driven by this air flow, the particles in nitrogen inflation or adhesion and corroded particles around the leak hole are inhaled into the leak hole to block the leak hole. All subsequent combination tests are found to be qualified (detection missing). During $100^{\circ} \mathrm{C}$ pre-baking process, the water vapor which entered and adsorbed by the internal surface and absorption material during the storage is released to the cavity and causes the internal water vapor reaching as high as $49 \%$. The reason might be this large gross-leak sample's leak hole was blocked during the test and the internal pressure of the IGA was significantly low. This would have to be confirmed by the NASA experimenter.

For another gross-leak sample b, its leak hole might be blocked, partially blocked or unstable after OLT. The UB gross-leak sample a in group 3 was the same as TO-18 gross-leak sample e in group 1, and TO-5 gross-leak sample c in group 2 was similar to TO-18 gross-leak sample b in group 1. The internal gas analysis data of the other 26 samples showed no signs of leak hole blockage or unstable leak hole existing. Among them, the samples of TO-5 and UB had severe leak, and their oxygen content was generally higher than $19 \%$. However, much of its water vapor escaped during pre-baking process before internal gas analysis and thus the water vapor content was low. The four samples that may have blocked, partially blocked or unstable leak holes are gross leak samples. The gross-leak holes are large, and the pressurized helium flow and reaerated flow are more likely to be viscous flow, which is easier to drive particles into the leak holes.

The explanation above indicates that based on the internal gas analysis data after multiple tests, the leak hole blockage, partial blockage or unstable leak hole samples accounted for $26.7 \%$ of the gross-leak samples and $13.3 \%$ of all the gross-leak and fine-leak samples. Therefore, majority of the detection missing were not caused by the leak hole blockage.

If it had been believed that all the detection missing were caused by the blockage of the leak hole, it then could not be explained why $100 \%$ UB samples were blocked during the CHLD and Kr85 fine-leak tests and 75.5\% TO-18 samples were blocked during the CHLD, K85 and OLT gross and fine-leak tests; while no single UB samples was blocked in the CHLD and Kr85 gross-leak test and no TO-5 sample blocked during the gross-leak and fine-leak CHLD test.

In cumulative helium mass spectrometry combination test, argon as gross-leak tracer gas and helium as fine-leak tracer gas combination test and intial or repeated helium mass spectrometry fine-leak test, there is indeed detection missing of the checked part due to leak hole blockage, but blockage is 
not the main cause of high rate detection missing of micro components. It is meaningful to analyze and study how to prevent the leak holes blockage and unstable leak hole. But it does not solve the fundamental problem of preventing high rate detection missing.

\section{Comparison of Various Sealability Test Methods}

Based on helium mass spectrometry test (HMS), radioactive $\mathrm{Kr} 85$ test and optical leak test (OLT), the latest American military standard $[15,16]$ selected CHLD, Kr85, and OLT three combination methods for highly sensitive test. Literature [31-34, 39] proposed a combination test by using argon as gross-leak tracer gas and helium as fine-leak tracer gas. The main features and application scope of them are compared as follows.

Kr85 test includes Kr85 combination test and Kr85 thermal combination test. In the formulas, the press-in and leakage of $\mathrm{Kr} 85$ are both counted as viscous flow. However, in the standard [15] method 1071.9 and the standard [16] method 1014.14 grade $\mathrm{K}$ and $\mathrm{CH} 1$, the equivalent standard leak rate criterion $\mathrm{L}$ has been generally $1 \times 10^{-3} \mathrm{~Pa} \cdot \mathrm{cm}^{3} / \mathrm{s}$ and $1 \times 10^{-4} \mathrm{~Pa} \cdot \mathrm{cm}^{3} / \mathrm{s}$. In the literature $[23,33,39]$, when the rigor grade $\tau_{\text {Hemin }}$ is 2000 days, the corresponding $\mathrm{L}_{\max }$ for the smaller inner cavity volume could reach the order of $10^{-5} \sim 10^{-6}$ $\mathrm{Pa} \cdot \mathrm{cm}^{3} / \mathrm{s}$. Inside this range of $\mathrm{L}$ or $\mathrm{L}_{\max }$, both of them should be molecular flow model.

The adoption of viscous flow is neither rigorous nor practical. Therefore, as pointed out in the literature [12], "Because of the difficulty in predicting the flow modes involved ... leakage rates determined by $\mathrm{Kr}-85$ tracer gas may vary by as much as one decade from rates measured by the helium mass spectrometer leak detector."

As shown in table 1, the three group of samples had been judged gross-leak or fine-leak in the first test, but in the repeated test of $\mathrm{Kr} 85$ the detection missing rate was up to $70 \%$, which is higher than that of $47.4 \%$ in the OLT combination test and $42 \%$ in the CHLD combination test.

Therefore, the theoretical model of gas exchange in $\mathrm{Kr} 85$ test should be reviewed and high rate of detection missing need to be addressed.

OLT method uses optical interference to detect the deformation of the upper surface caused by tracer gas leaked into the component under the constant pressure. This method is not affected by adsorption helium leak rate, and is suitable for encapsulation with deformable metal or ceramic top cover, and can be used for matrix test of micro-small devices integrated on the wafer. This method uses HMS and CHLD for comparison and calibration and test results could be mutually verified. However, as can be seen from table 1, the OLT combination test method shows that there are no data for 10 pieces of UB package samples with inner cavity volume of $0.0026 \mathrm{~cm}^{3}$, and for 1 out of $10 \mathrm{TO}-18$ package samples with inner cavity volume of $0.0345 \mathrm{~cm}^{3}$. OLT combined test has limitation when applying to small inner cavity volume. In the applicable range of OLT combination test has higher detection missing rate than CHLD combination test. Literature [12] considers that "OLT should undergo additional qualification testing prior to its inclusion into the seal test methods".

Using the methods stated in chapter 5 to reduce and prevent detection missing in gross-leak test and chapter 6 in fine-leak test, a fixed scheme could be designed for cumulative helium mass spectrometry combination test (CHLD). While taking $\mathrm{R}_{0 \max }$ as $1 \times 10^{-4} \mathrm{~Pa} \cdot \mathrm{cm}^{3} / \mathrm{s}$ and $1 \times 10^{-3} \mathrm{~Pa} \cdot \mathrm{cm}^{3} / \mathrm{s}$, corresponding $\mathrm{L}_{0}$ as $7.07 \mathrm{~Pa} \cdot \mathrm{cm}^{3} / \mathrm{s}$ and $70.7 \mathrm{~Pa} \cdot \mathrm{cm}^{3} / \mathrm{s}$, the range of internal cavity volume applicable to pressing helium method is $0.06 \mathrm{~cm}^{3} \sim<$ $200 \mathrm{~cm}^{3}$ when $\tau_{\mathrm{Hemin}}=2000 \mathrm{~d}$, and $0.6 \mathrm{~cm}^{3} \sim<200 \mathrm{~cm}^{3}$ when $\tau_{\text {Hemin }}=200 \mathrm{~d}$. It can hardly be applicable to $\tau_{\mathrm{Hemin}}=20 \mathrm{~d}$; the range of inner cavity applicable to the prefilling helium method is $0.06 \mathrm{~cm}^{3} \sim<20 \mathrm{~cm}^{3}$ when the $\tau_{\mathrm{Hemin}}=2000 \mathrm{~d}$, it can hardly be applicable to $\tau_{\mathrm{Hemin}}=200 \mathrm{~d}$ and $\tau_{\mathrm{Hemin}}=20 \mathrm{~d}$. The rigor grade and inner cavity volume that can be applied in CHLD combination test are seriously limited.

The combination test method by using argon as gross-leak tracer gas and helium as fine-leak tracer gas can correctly distinguish gross-leak and fine-leak, and can detect $\mathrm{R}_{\max }$ larger than the $\mathrm{R}_{0 \max }$ corresponding to $\mathrm{R}_{\mathrm{Ar} 0 \max }$. As the fixed scheme described in literature [39], when taking $\mathrm{R}_{\mathrm{Ar} 0 \max }$ as $7.94 \times 10^{-4} \mathrm{~Pa} \cdot \mathrm{cm}^{3} / \mathrm{s} \sim 2.39 \times 10^{-2} \mathrm{~Pa} \cdot \mathrm{cm}^{3} / \mathrm{s}$ corresponding $\mathrm{L}_{0}$ as $0.1 \mathrm{~Pa} \cdot \mathrm{cm}^{3} / \mathrm{s} \sim 3 \mathrm{~Pa} \cdot \mathrm{cm}^{3} / \mathrm{s}$, the range of inner cavity volume applicable to the pressing helium-argon after prefilling argon method is $0.002 \mathrm{~cm}^{3} \sim<200 \mathrm{~cm}^{3}$ when the $\tau_{\mathrm{Hemin}}=2000 \mathrm{~d}$, $0.0006 \mathrm{~cm}^{3} \sim<200 \mathrm{~cm}^{3}$ when the $\tau_{\mathrm{Hemin}}=200 \mathrm{~d}$, and $0.002 \mathrm{~cm}^{3} \sim$ $<60 \mathrm{~cm}^{3}$ when the $\tau_{\mathrm{Hemin}}=20 \mathrm{~d}$. The range of inner cavity volume applicable to the prefilling helium-argon method is $0.0006 \mathrm{~cm}^{3} \sim<200 \mathrm{~cm}^{3}$ when $\tau_{\mathrm{Hemin}}=2000 \mathrm{~d}, 0.002 \mathrm{~cm}^{3} \sim<$ $200 \mathrm{~cm}^{3}$ when $\tau_{\text {Hemin }}=200 \mathrm{~d}$, and $0.002 \mathrm{~cm}^{3} \sim<6 \mathrm{~cm}^{3}$ when $\tau_{\text {Hemin }}=20 \mathrm{~d}$.

On the premise of reducing gross-leak detection missing rate and preventing fine-leak detection missing, the combination test method by using argon as gross-leak tracer gas and using helium as fine-leak tracer gas effectively expands the applicable $\tau_{\text {Hemin }}$ and inner cavity volume $\mathrm{V}$ range. It meets the requirements of sealability test with different rigor grades and its applicable range is significant bigger than the combination test methods of CHLD, Kr85 or OLT. Of course, in order to prevent detection missing and misjudgment, unstable leak hole need to be avoided from structural design and process control. Such leak hole will present different standard leak rate $\mathrm{L}$ under different internal and external pressure. It is also necessary to prevent the blockage of leak hole and the generation of new leak hole in the test environment and methodology.

In order to apply this combination test method by using argon as gross-leak tracer gas and helium as fine-leak tracer gas, more study related to patents [33, 39] and relevant papers. The invention in these patents could be used to develop the argon gross-leak and helium fine-leak combination detector. The differential pressure leak detector could be improved to detect larger gross-leak. In this way, the sealability test methods and processes are improved so that gross and fine-leak detection missing can be effectively prevented and range of applicable 
rigor grades and inner cavity volume are extended.

It has been found $[6,12,14]$ that the result of the internal gas analysis and test results of HMS, CHLD and OLT could be used for mutual verification. Because the internal gas analysis has higher test sensitivity, based on the molecular flow model of internal and external gas exchange, literature [28] and patent [29] proposed "An internal gas mass spectrometry analyzing method for sealability test of components" which could be used on higher accuracy and allowing destructive testing occasions.

\section{Conclusion}

This paper proposed a series of improvements on helium mass spectrometry sealability test. They include taking rigor grade $\tau_{\mathrm{Hemin}}$ which is minimum helium exchange time constant of accepted components, as basic criterion for fine-leak test, quantitative determination of maximum detection-waiting time for fine-leak test, a combination test method by using argon as gross-leak test tracer gas and helium as fine-leak test tracer gas as the core improvement, methods of reducing and preventing detection missing in gross-leak test and in fine-leak test. Those improvements break through the common problems of unevenness of reliable storage life time for accepted components, low feasibility of removing absorbed helium during test and compromised reliability due to high rate of detection missing.

It is a process to adopt research results to industry sealability test standards. It requires attention and effort from the experts in the field for further improvements, developing combination leak detector by using argon as gross-leak test tracer gas and helium as fine-leak tracer gas as the application of invention patent [33, 39] and improving differential pressure leak detector as supplement gross-leak test for lager leakage. Only through the joint effort of all parties related to sealability test, the research results could improve the industry standards and change the "embarrassment" situation of current standards in the helium mass spectrometry test.

\section{Acknowledgements}

Thanks to Beijing keytone Electronics Relay Corporation for supporting this research over years by providing facilities and most of the funding. Thanks to the cooperation of Beihang University, No.4 electronics academy of China and Inficon company. Thanks to the precious support of relevant scholars, and technical experts. Especially, thank Mr. Datong Xue for further improvement of quantitative determining maximum detection-waiting time formula proposed by Wang's team, Mr. Qi An for simplifying the formula of inner helium partial pressure after multi-pressing helium, and $\mathrm{Mr}$ Rudi Widt for providing the argon standard leak hole. Thanks to Mr. Pengzhou Zheng, Mr. Xiaojian Wu and Mr. Xihui Cui for long-term supporting and review of our reports and papers. Special thanks to Mrs. Jianhua Wang for reviewing the paper.

\section{References}

[1] J. Gordond. Davy, "Calculations for Leak Rate of Hermetic Package", IEEE 1975.

[2] Stroehle. D, "On the Penetration of Gases and Water Vapour into Packages with Cavities and on Maximum Allowable Leak Rates", IEEE 1978.

[3] Hal Greenhouse, "Hermeticity of Electronic Package", Willam Andrew Publishing USA, 2000, PP.1-402.

[4] Genglin Wang, "Research for Sealability Test Method of Components", Electronic Standardization \& Quality, ISSN 1004-9586, Beijing, 2000 (6), pp. 30-33, 40/2001 (1), pp. $36-40$.

[5] Genglin Wang, W. L D. L. "Study on Leak Rate Formula and Criterion for Helium Mass Spectrometer Fine Leak Test". IEEE 2007.

[6] Genglin Wang, Liyan Wang and Lijun Dong, "Study on the Relationshiop between Internal Water Vapor Content and Sealability of Electronic", Electronic Component \& Device Applications. ISSN1563-4795, Xian, Feb.2009, Vol.11, NO.2, pp.78-81.

[7] Genglin Wang, Fei Li, Caiyi Wang and Ningbo Li, "Experiment and Analysis of Bubble Method for Gross Leak Test", Electronic Product Reliability And Environmental Testing, ISSN1672-5468, Guangzhou, Nov.2013, Vol.31, Add.1, pp. 4-10.

[8] IEC 68-2-17, Basic Environmental Testing Procedures Part 2: Test-Test Q: Sealing. 1994.

[9] Thomas J. Rossiter, "Searching for Leakers". JEDEC, May 2008.

[10] Alan Barone, "IC Moisture Content Issues", Components for Military \& Space Electronics Conference Notes, February7-10, 2011.

[11] Robert Lowry, "Hermeticity and RGA", Components for Military \& Space Electronics Conference Notes, February 7-10, 2011.

[12] Aaron, C, Der Marderesian Jr. C, "Gross Leak testing challenges for hermetic \& sealed electronic assemblies", Components for Military \& Space Electronics Conference Notes , February 9, 2011.

[13] Patricka Mc Manus, Kathy Pressnell, Lyudmyla Panashchenko, "Hermeticity Task Overview", NASA Electronic Parts and Packaging (NEPP), June 11, 2013.

[14] Kathy Laivd, Patrick McManus, Lyudmyla Panashohenko, "Joint Hermeticity Correlation study", NASA Electronic Parts and Packaging (NEPP), June 17, 2014.

[15] MIL-STD-750-1 Department of defense Test Method Standard Methods for Semiconductor Devices Method 1071.9Hermetic Seal, 2012.

[16] MIL-STD-883J Department of Defense Test Method Standard Microcircuits Method 1014.14 Seal, 2013.

[17] Genglin Wang, Fei Li, Ningbo Li and Yongmin Liu, "Removing Absorbed Helium Testing and its Related Standards", Electronic Product Reliability And Environmental Testing, ISSN1672-5468, Guangzun, Dec.2013, Vol.31, NO.6, pp.5-12. 
[18] Genglin Wang, Ningbo Li, Lijun Dong and Fei Li, "A Study and Commentary on NASA Electronic Parts and Packaging Hermeticity Task Overview", Electronic Product Reliability And Environmental Testing, ISSN1672-5468, Guangzun, Apr.2015, Vol.33, NO.2, pp.6-13.

[19] Alan Barone, "IC Moisture Content Issues", Components for Military \& Space Electronics Conference Notes, February7-10, 2011.

[20] Aaron C. Der, Marderosina Jr, "Questions? ", Components for Military \& Space Electronics Conference Notes, February 7-10, 2011.

[21] Howl, D. A and Mann, C. A, "The Back-Pressurizing Technique of Leak-Testing", Vacuum, 1965, vol15, NO.7, PP.347-352.

[22] Genglin Wang, Fei Li, Caiyi Wang, Ningbo Li, Liyan Wang, Lijun Dong and Yongmin Liu, "Base Criterion and Maximum Dwell Time of Fine Leak Test Using the Helium Mass Spectrometer Leak Detector", Journal of China Academy of Electronic and Information Technology, ISSN1673-5692, Beijing, Apr.2013, Vol.8, NO.2, pp.213-220.

[23] Applicant: Beijing Keytone Electronic Relay Corporation, Inventors: Genglin Wang, Fei Li, Caiyi Wang, Ningbo Li, Method for Helium Mass Spectrometric Fine-Leak Test Besed on Quantitative Determination of Maximum Test-Waiting Time, Chinese invention patent No: ZL 201310047094.3, Application date 06/02/13, Authorization Date 28/12/16. United States invention patent No:14/93.658, Filed 06/12/13, Date of Patent 06/06/17.

[24] Qi An and Xiaoyu Luo, "Analysis of Leak Test with Helium Mass Spectrometer", Electronic Product Reliability And Environmental Testing, ISSN1672-5468, Guangzhou, Aug.2014, Vol.32, NO.4, pp.34-38.

[25] Genglin Wang, Fei Li, Ningbo Li and Yongmin Liu, "Fixed Scheme Design of Helium Mass Spectrometric Fine Leak Detection for Pressing Helium Method and Prefilling Helium Method", Journal of China Academy of Electronics and Information Technology, ISSN1673-5692, Beijing, Dec.2013, Vol.8, NO.6, pp.656-660.

[26] Applicant: Beijing Keytone Electronic Relay Corporation, Inventors: Genglin Wang, Ningbo Li, Fei Li, Yongmin Liu, A Method for Multi-Pressing Helium and Pressing Helium after Prefilling Helium Mass Spectrometric Fine Leak detection. Chinese invention patent No: ZL 20131016115.4, Application date 03/05/13, Authorization Date 04/07/17.

[27] Genglin Wang, Ningbo Li, Fei Li and Yongmin Liu, "Helium Mass Spectrometric Fine Leak Detection Methods Research for Multi-Pressing Helium Method and Pressing Helium after Prefilling Helium Method", Journal of China Academy of Electronics and Information Technology, ISSN1673-5692, Beijing, Feb.2014, Vol.9, NO.1, pp.105-109.

[28] Genglin Wang, Fei Li, Ningbo Li and Yongmin Liu, "An Internal Gas Mass Spectrometric Analyzing Method for Sealability Test of Components", Journal of China Academy of Electronics and Information Technology, ISSN1673-5692, Beijing, Jun.2014, Vol.9, NO.2, pp.325-330.
[29] Applicant: Beijing Keytone Electronic Relay Corporation, Inventors: Genglin Wang, Fei Li, Ningbo Li, Yongmin Liu, Method for Detecting the Sealing Properties of Components by Internal Gas Mass Spectrometry analysis, Chinese invention patent No: ZL 201310504713.7, Application date 23/10/13, Authorization Date 11/01/17.

[30] Applicant: Beijing Keytone Electronic Relay Plant, Inventors: Genglin Wang, Fei Li, Ningbo Li, A Method for Detecting the Sealing Properties of Components by Accumulating Helium Mass Spectrometry gross-leak and fink-leak Combination test, Chinese invention patent No: ZL 201310303714.5, Application date 18/07/13, Authorization Date 11/05/16.

[31] Genglin Wang, Ningbo Li, Fei Li and Lijun Dong, "A Method of Cumulative Helium Gross/Fine Combination Test by Using Argon as Gross-Leak Tracer Gas", Journal of China Academy of Electronics and Information Technology, ISSN1673-5692, Beijing, Aug.2015, Vol.10, NO.4, pp.436-441/447.

[32] Genglin Wang, Ningbo Li, Lijun Dong and Fei Li, "Quantitative Expansion of the Maximum Detection-waiting Time in Helium Mass Spectrometer Fine-leak Test", Journal of China Academy of Electronics and Information Technology, ISSN1673-5692, Beijing, Det.2015, Vol.10, NO.6, pp.48-54.

[33] Applicant and Inventors: Genglin Wang, Ningbo Li, Fei Li, Method of Cumulation Helium Mass Spectrometric Combination Test by Using Argon as Gross-Leak Tracer Gas, Chinese invention patent No: ZL 201310404443.2, Application date 06/09/13, Authorization Date 08/02/17, United States invention patent No:14/134.006, Filed 19/12/13, Date of Patent $16 / 05 / 17$.

[34] Genglin Wang, Ningbo Li, Lijun Dong, Fei Li and Yongmin Liu, "Methods of Preventing Detection Missing in Accumulative Helium Mass Spectrometry Combination Test", Journal of China Academy of Electronics and Information Technology, ISSN1673-5693, Beijing, Aug.2016, Vol. 11, NO. 4, pp. 407-416.

[35] Yudai Liu, "Vacuum Measurement and Testing", China Metallurgical Industry Publishing House, Beijing, 1992.

[36] Xiangzheng Xiao, "Leakage Detection Technology and Application", China Machine Publishing House, Beijing, 2009.

[37] Datong Xue and Xiangzheng Xiao, "Upper Limit of Equivalent Standard Leakage Rate for Hermetically Sealed Devices Detected by Pressing or Prefilling Helium Method ", Chinese Journal of Vacuum Science And Technology, ISSN1672-7126, Beijing, 2013, Vol.33, NO.8, pp.721-729.

[38] Daoan Da, "Vacuum Design Manual", China National Defense Industry Editora , Beijing, 2004, pp.106-111.

[39] Applicant and Inventors: Genglin Wang, Ningbo Li, Lijun Dong, A Combination Test Method by Using Argon as Gross-Leak Test Tracer Gas and Using Helium as Fink-Leak Test Tracer Gas, Chinese invention patent No: ZL 201510199700.2, Application date 23/04/15, Authorization Date 08/09/17, United States invention patent No:14/971.623, Filed 12/16/15, Date of Patent 01/04/19. 